Hans-Hellmut Neumayer • Friedrich C. Luft

\title{
Twenty-five years of renal transplantation from a single center: a risk factor analysis for short- and long-term outcomes
}

Published online: 23 December 2005

(C) Springer-Verlag 2005

The online version of the original article can be found at http://dx. doi.org/10.1007/BF00186622

Written on behalf of the Transplantationsgruppe Mittelfranken

H.-H. Neumayer $(\bowtie)$

Medizinische Klinik mit Schwerpunkt Nephrology,

Charité Campus Mitte, Universitätsmedizin Berlin,

Schumannstrasse 20/21,

10117 Berlin, Germany

e-mail: hans-h.neumayer@charite.de

Tel.: +49-30-450514072

F. C. Luft

Medizinische Klinik mit Schwerpunkt Nephrologie und

Hypertransiologie, Charité Campus Berlin-Buch,

Universitätsmedizin Berlin, and Franz Volhard-Klinik,

HELIOS-Kliniken Berlin,

Wiltbergstrasse 50 ,

13125 Berlin-Buch, Germany
Clin Investig (1993) 71:341-350

Inadvertently, the individual authors of this paper were never provided. This specification of authorship has been published with the intention to improve accessibility of the article. 